\title{
Cervantes y \\ el mundo moderno
}

Juan Durán Luzio ${ }^{1}$

Universidad Nacional, Costa Rica

\section{RESUMEN}

Se analiza el papel desempeñado por la gran novela cervantina en el subsecuente desarrollo de la narrativa moderna hasta la actualidad. La aventura del héroe, en aquella célebre novela, adopta un sentido actual profundamente simbólico, que todavía tiene vigencia, porque apunta a lo conocido, a lo cotidiano, a lo posible.

\section{Abstract}

An analysis is carried out on the role of Cervantes' great novel in the subsequent development of modern narrative up to the present time. The adventure of the hero in that famous novel adopts a highly symbolic sense which remains valid because it addresses what can be considered familiar, well known and possible.

Palabras clave: Cervantes, novela moderna, verosimilitud literaria.

Keywords: Cervantes, modern novel, literary verisimilitude.

El pensador español José Ortega y Gasset publicó en Madrid en 1914 un conjunto de ensayos titulado Meditaciones del Quijote; este libro siguc contando hoy, a mi juicio, entre las mejores interpretaciones del

( orreo clectrónico: duranluzio@hotmail.com. 
Quijote. En una de esas inteligentes reflexiones, Ortega afirma que desde la cumbre del Renacimiento, a fines del siglo XVI, «el arte se enriquece con un término más; por decirlo así, se aumenta en una tercera dimensión, conquistando la profundidad estética, que, como la geométrica, supone una pluralidad de términos...». Y añade Ortega y Gasset, líneas más adelante, que "ya no puede, en consecuencia, hacerse consistir lo poético en ese peculiar «atractivo del pasado ideal ni en el interés que a la aventura presta su proceder, siempre nuevo, único y sorprendente. Ahora tenemos que acomodar en la capacidad poética la realidad actual», es decir, incluir y expresar literariamente la compleja e inédita vida ordinaria de todos los días ${ }^{2}$.

Dos breves explicaciones son necesarias en este punto: el pasado ideal y la aventura son componentes medulares de las novelas de caballería; el otro, es el héroe invencible que, viviendo en ese pasado ideal, ejecuta aquellas aventuras tan sorprendentes como increíbles.

El pasado ideal es el tiempo de la leyenda, del cuento de hadas, del «érase una vez un reino...» o el del «había una vez, hace muchos, muchos años...»; es decir, aquel aludido con estas fórmulas consagradas para épocas remotas e imprecisas que no se pueden fijar en ninguna cronología de la historia, pero figuran en la cronología mítica de muchos pueblos.

$\mathrm{Y}$ en cuanto a la aventura siempre nueva, única y sorprendente, digamos que, además de crear "una tensión emocional creciente» permite al héroe invencible derrotar a su paso dragones, hechiceros, magos y gigantes, y le permite cruzar mares tempestuosos o trepar elevados muros de castillos enemigos, sin grandes demoras. Esta aventura sorprendente nos es familiar porque continúa habitando entre nosotros en una forma de cine donde sus personajes no se llaman ya Amadís de Gaula o Felixmarte de Hiscarnia, sino Arnold Schwarzenegger o Silvester Stallone. \begin{tabular}{ll}
\hline José Ortega y Gasset, Meditaciones del Quijote. Con comentario de Julián Marías (Madrid: \\
Revista de Occidente, 1957), 147.
\end{tabular} 
Y si alguna vez aquellos héroes de las caballerías tuvieron antecedentes reales, y de allí su arraigo en la mente de las gentes, fue en las figuras medievales de un Roland, en la corte de Carlomagno, o de un Ruy Díaz de Vivar, el Cid Campeador; pero a fines de la Edad Media ese legado heroico se extinguía y era reemplazado por descendientes ficticios de aquellos héroes, a quienes la invención de la imprenta, entre 1454 y 1456 , dio identidad definida y permanente: esta nueva clase de personajes pasó a poblar muy exitosamente las páginas de las novelas de caballerías, las mismas que fascinaban a don Quijote. En efecto, se calcula que antes del año 1500 aparecieron unos 20.000 títulos en Europa; de ellos, un gran número fueron novelas de caballería, porque ya tenían sus lectores y un mercado amplio, puesto que venían circulando en forma manuscrita desde la Edad Media.

Pero, ¿qué es una novela de caballería? Una novela de caballería es básicamente un relato en prosa, extenso, de aventuras consecutivas, de hazañas inverosímiles y fantásticas ejecutadas por un héroe joven, fuerte, enamorado y bello e invencible, en un pasado ideal, tan remotamente lejano que hacía todas tales fantasías creíbles. En suma, un género siempre igual, predecible, sin perspectiva ni profundidad.

¿Cuál es, pues, la contribución de Cervantes? ¿Qué vías abre su invención en ese cruce de vías que es el Renacimiento? Creo que la contribución de Cervantes ha sido abrir las puertas de la novela - y del arte- hacia el mundo moderno que comenzaba, hacia esa tercera dimensión desconocida, como Colón y Vespucio abrieron las de una geografía hasta entonces plana, como Copérnico - muerto cinco años antes de que naciera Cervantes-abrió las de la física y la astronomía instalando el sol en el centro de los cielos, como Miguel Servet abrió las de la medicina, al descubrir que la sangre circulaba por el cuerpo, impulsada por esa bomba de músculos que era el corazón, y esto, para pagar después el hallazgo con su vida, en la hoguera inquisitorial del ('illvinismo, en Ginebra, en $1553^{3}$.

( 'oIII) immpliando la noción del hallazgo cervantino hacia una dimensión más prof unda, detrás de lo conocido, Michel Foucault escribe lo siguiente, situando esa noción en la autonomía del 
Para ilustrar el procedimiento detallado de esa hazaña de Miguel de Cervantes Saavedra, voy a valerme de las primeras treinta líneas de su célebre novela y les invito, pues, a una lectura conjunta. He aquí el texto, acaso ya sabido por buena parte de los lectores:

\section{Capítulo I}

Que trata de la condición y ejercicio del famoso y valiente hidalgo don Quijote de la Mancha.

1- En un lugar de la Mancha, de cuyo nombre no quiero acordarme, no ha mucho tiempo que vivía un hidalgo de los de lanza en astillero, adarga antigua, rocín flaco y galgo corredor. 2- Una olla de algo más vaca que carnero, salpicón las más noches, duelos y quebrantos los sábados, lentejas los viernes, algún palomino de añadidura los domingos, consumían las tres partes de su hacienda. 3- El resto de ella concluían sayo de velarte, calzas de velludo para las fiestas, con sus pantuflos de lo mismo, y los días de entresemana se honraba con su vellorí de lo más fino. 4- Tenía en su casa un ama que pasaba de los cuarenta y una sobrina que no llegaba a los veinte, y un mozo de campo y plaza que así ensillaba el rocín como tomaba la podadera. 5- Frisaba la edad de nuestro hidalgo con los cincuenta años. 6- Era de complexión recia, seco de carnes, enjuto de rostro, gran madrugador y amigo de la caza. 7- Quieren decir que tenía el sobrenombre de Quijada o Quesada, que en esto hay alguna diferencia en los autores que de este caso escriben, aunque por conjeturas verisímiles se deja entender que se llamaba Quijana. 8- Pero esto importa poco a nuestro cuento:

lenguaje: «Don Quijote es la primera de las obras modernas, ya que se ve en ella la razón cruel de las identidades y de las diferencias juguetear al infinito con los signos y las similitudes; porque en ella el lenguaje rompe su viejo parentesco con las cosas para penetrar en esa soberanía solitaria de la que ya no saldrá, en su ser abrupto, sino convertido en literatura; porque la semejanza entra allí en una época que es para ella la de la sin razón y de la imaginación». Las palabras y las cosas. Trad. de Elsa Cecilia Frost. 15 ed. (México: Siglo xxı, 1984). 55. 
basta que en la narración de él no se salga un punto de la verdad. 9- Es, pues, de saber que este sobre dicho hidalgo, los ratos que estaba ocioso - que eran los más del año— se daba a leer libros de caballerías, con tanta afición y gusto, que olvidó casi de todo punto el ejercicio de la caza y aun la administración de su hacienda; y llegó a tanto su curiosidad y desatino en esto que vendió muchas fanegas de tierra de sembradura para comprar libros de caballerías en que leer, y así, llevó a su casa todos cuantos pudo haber dellos.

La primera frase todos nos la sabemos de memoria: «En un lugar de la Mancha, de cuyo nombre no quiero acordarme, no ha mucho tiempo que vivía un hidalgo de los de lanza en astillero, etc.» En primer término, La Mancha es ya una mención a un espacio no solo conocido por cualquier lector español, sino dicha además la frase en un tono coloquial y muy personal, por aquello de no querer acordarse; es una mención a un espacio corriente, de escaso prestigio histórico. La Mancha, en Castilla la Nueva, era una región de incorporación relativamente reciente al auge de la nueva nación española surgida luego de la Reconquista, la cual no gozaba aún de mayor reputación histórica ni cultural; es como si Cervantes hubiese elegido cualquier lugar de los menos notorios y prestigiosos de la España de su tiempo $\mathrm{y}$, por otra parte, casi anónimo: «En un lugar de La Mancha...». Y luego agrega: «de cuyo nombre no quiero acordarme»; esto ha dado pie a los cervantistas para especular si Cervantes alguna vez fue maltratado allí, o si permaneció preso en ese sitio, o si hay algún rasgo secreto por el cual él no hubiese querido llenar de gloria algún pueblón de La Mancha ${ }^{4}$. Pero, sobre todo, desde el punto de vista del análisis litcrario nos interesa aquí un hecho indudable: el dominio, el control

La noción de patria y el sentido de la importancia geográfica de aquella España es analizado por Antonio Feros en «Por Dios, por la Patria y el Rey: el mundo político en tiempos de Cervantes», Antonio Feros y Juan Gelabert, eds. España en tiempos del Quijote (Madrid:Taurus, 2005), en especial, 76-87. 
y la preponderancia que el narrador declara sobre su discurso. Este es un nuevo tipo de narrador, que va a ejercer ya su total autoridad sobre el texto que escribe, sin hacer concesiones a la retórica, ni a las convenciones previas, ni tampoco a un modo narrativo exitoso, que era el modo tópico de las novelas de caballería, donde se hablaba solo de espacios legendarios o muy tradicionales. Aquí el narrador se limita a decir «no quiero acordarme» sin más; simplemente lo omite como para subrayar el poder de su voluntad.

Luego pasa a introducir a su personaje: «No ha mucho tiempo que vivía un hidalgo de los de lanza en astillero...». Antes, comparemos los verbos: «no quiero acordarme» está en presente de indicativo, es decir, no quiero acordarme ahora, en este momento que escribo, y luego la reiteración de un uso verbal casi en presente, «no ha mucho tiempo que vivía», es decir, como si estuviese hablando de hechos cercanos, de hechos presentes; es como si postulara que tal vez todavía vive ese hidalgo por allí.

Luego califica el contexto de ese hombre: «Un hidalgo de los de lanza en astillero, adarga antigua, rocín flaco y galgo corredor». La primera frase sitúa un colectivo social, «hidalgo de los de...»; es decir, hay muchas personas como él, son comunes. Luego la frase calificativa "de lanza en astillero»: una lanza inactiva, que ya no se usa; y una «adarga antigua», un añoso escudo de piel, aludiendo por ambos objetos en desuso a un cierto prestigio militar, de un hidalgo y cristiano viejo, con hidalguía ganada por padres o abuelos en la pasadas guerras de reconquista, pero ya gloria también pasada. Ahora el «rocín flaco», supone un caballo de pobres, de uso diverso y diario, más de agricultura que de monta y, claro, no en muy buen estado. Por cierto se despliega aquí el sutil efecto humorístico de la frase al evocarse, por oposición, los caballos legendarios de grandes personajes, sean los de la historia o los de la ficción.

De seguido incluye el narrador una información sorprendente y del todo inusual en la novelística de entonces - con excepción honrosa de El Lazarillo de Tormes, que desde 1554 contribuiría con 
Cervantes a fundar el realismo literario- que es una clara señalización del tipo diverso de novela que se ha propuesto el autor: se detallan las comidas de este hidalgo, digamos, de clase media: este es un hombre que, como todos los demás hombres comunes y corrientes, come. Y come la dieta habitual en la España de sus días y de sus medios: de primero, una «olla de algo más vaca que carnero» - en ese tiempo era más barata la carne de vaca que la de carnero, por el precio de la lana-; esta sopa común entonces, es la tatarabuela de la olla de carne que comemos en Costa Rica. Después, «salpicón las más noches», plato hecho a base de lo que había quedado del almuerzo, en especial la carne picada con cebolla, aliñada con sal y vinagre. Es decir, en casa no acomodada como la suya no era como para cenar cambiando el menú, sino que se repetía lo que había quedado del mediodía. «Duelos y quebrantos los sábados», como discuten los especialistas, al parecer, huevos con tocino o huevos con jamón, pero esto solo una vez a la semana; «lentejas los viemes», respetando así la dieta católica, tan común del pueblo español y exigida en esa España de la Contrarreforma; «algún palomino de añadidura los domingos», así, para engalanar la mesa del día de asueto, un pichón de paloma, y todo eso consumía las tres cuartas partes de su hacienda. Al especificar estos detalles, es evidente que Cervantes hace hincapié en lo propio de la dieta de una familia de clase media media, diríamos ahora. ¿Y por qué este tipo de información? Porque esta es su realidad y la realidad que reconoce como propia y no fantasiosa cualquier lector de esos días. La verosimilitud se impone y de este modo la vida cotidiana empieza a imponer el peso de su verdad y el halo de su atractivo en la literatura.

Ciertamente el personaje es un hidalgo, es decir, de familia conocida y respetable; pero esto no es mayor nota de distinción porque hay mucho hidalgo empobrecido ya en la España de mitad del siglo xvı. Que sea hidalgo apunta aquí a su origen de familia antigua y entroncada con la nobleza y, sobre todo, sin sangre judía en sus venas. ( 'omo se ve, no por ser hidalgo se es rico, sino que éste más bien era 
un señor empobrecido, residente en un pueblo desconocido, cuyo nombre ni siquiera amerita ser recordado por el narrador. Y desde aquí surge el atractivo de una de las metas que persigue Cervantes: el personaje, con cada línea, se va haciendo más real, o más creíble ante los ojos de un sorprendido lector, acostumbrado a las excesivas fantasías de las caballerías y a sus héroes inverosímiles que no necesitan de comidas ni de menudencias parecidas.

Continúa después el narrador afirmando que «El resto de ella (de su hacienda), concluían sayo de velarte, calzas de velludo para las fiestas, con sus pantuflos de lo mesmo y los días de entre semana se honraba con su vellorí de lo más fino». La frase enumera los pocos vestidos del personaje: otro detalle inesperado a menos que fuesen armaduras o cotas de malla, pero este hombre posee un sayo o capa común, de tela fuerte, el velarte, sus medias altas y zapatos iguales, para ocasiones especiales y uno de dominguear, —el día entresemana, aunque de vellorí, que es un tipo de tela barata por esos años, aunque Cervantes pone a don Quijote a usar una tela un poco mejor que la más barata de todas: "de lo más fino», añade solidario. Otra vez se trata de connotaciones precisas que indican la condición económica del personaje: queda más que claro que no es rico, ni un gran noble, como los héroes de caballería; ni es hijo desconocido de un rey, ni tiene ninguno de los otros rasgos que adornan a aquellos caballeros.

Pero a este señor más bien pobre y de pasar mediano, se le da ya el singular rasgo narrativo de ser perfectamente reconocible por cualquier lector de su época. Para el lector de entonces, este es un señor como algún coterráneo suyo, quien sorprendentemente viste lo consabido y come lo mismo que en su casa, que en su familia, que sus vecinos. La magia del párrafo consiste en que su dieta y sus vestidos son los usuales, los que cualquier lector español del momento reconoce como propios. Así, el escenario convencional de la literatura narrativa comienza a ser reemplazado por un escenario sorprendente; pero sorprendente por lo conocido.

Informa después la narración: "Tenía en su casa un ama que pasaba de los cuarenta, y una sobrina que no llegaba a los veinte, y un 
mozo de campo y plaza, que así ensillaba al rocín como tomaba la podadera». Era casi obligatorio que un hidalgo tuviese sirvientes, pero aquí no los hay especializados, como en casa grande; este mozo ayuda en todo y el ama está también a manera de asistente general de la familia. Otra vez, a pesar de esas simetrías que encantan a Cervantes - «cuarenta y veinte» 0 acaso gracias a ella, se ha creado una firme ilusión de lo real: el contexto es del todo reconocible para el lector de sus días; como si la realidad reclamara su lugar en estas líneas, o como si estas líneas vertieran su halo de realidad sobre la imaginación de un lector, quien sabrá situar su contraparte fuera del texto. Este es el efecto del espejo barroco, como el efecto que nos causa contemplar Las meninas, de Velázquez, cuadro pintado unos diez años después de muerto Cervantes: la realidad circundante y los recursos para su inclusión en la obra pesan tanto o más que el supuesto tema central de la obra.

Ahora viene algo asombroso, y esto sí es una inesperada novedad para muchos de entonces; además de la comida, la dieta, el modo de vestir, los sirvientes, la región de don Quijote, se dice algo que debió de haber golpeado a sus lectores de 1605, algo que tal vez los dejó perplejos: «Frisaba la edad de nuestro hidalgo con los cincuenta años». Nótese que Cervantes deja la quinta frase aparte, como autónoma en la oración, la cual, hábilmente, ejerce su esperado efecto particular: no hay héroes de cincuenta años; todavía hoy casi no hay héroes literarios de cincuenta años; si los hay, será excepcionalmente. Se estilaba que cl caballero andante empezara su vida de guerrero desde los catorce o quince años: esos son los Amadís de Gaula; ese es don Galaor, ese es don Palmerín de Oliva: todos, cuando más, tienen veinte años y representan una especie de equivalencia entre la plenitud física y estética y la edad del personaje, tal como hoy lo aparentan Silvester o Arnold. Desde luego, aquellos consabidos caballeros andantes eran hírocs más en sus proezas que en sus ideales; solo saben combatir el IIIal con sus brazos poderosos; este señor de cincuenta años se propone (ombatir el mal claro, pero, a pesar de su débil brazo, aspira a reformar 
la realidad. Y será héroe porque su empeño consiste en «querer él, ser él mismo», a pesar de todo, siempre fiel a sus ideales, como señala Ortega (p. 159). Y más que héroe él mismo, es su lucha la heroica; y en tal caso no importa la edad. ¡Qué paradoja: este flacuchento señor de cincuenta años iba a convertirse en el héroe por antonomasia de la nueva literatura universal, relegando el atractivo de la fuerza y la belleza fisicas a una segunda categoría!

La notable frase «Frisaba la edad de nuestro hidalgo con los cincuenta años» nos debe detener ahora en el adjetivo posesivo «nuestro»; otro sobresalto: es «nuestro hidalgo». Esto lleva al lector a asumir que el uso del posesivo «nuestro» porta la idea de que Cervantes se alinea con él, que el narrador lo sitúa en su bando y, sobre todo, lo sitúa en el bando del lector, incluido también en el posesivo. El héroe al que debemos acompañar será, pues, un hidalgo provinciano, pobretón y en declive: ninguna victoria está asegurada. Además, claro, se sabe que aquella era una edad bastante avanzada para esa época.

Luego se añade que nuestro héroe «era de complexión recia, seco de carnes, enjuto de rostro, gran madrugador y amigo de la caza». No hay en su reseña ningún atributo de belleza fisica antes al contrario, aunque fuerte, pareciera más bien feo o nada agraciado, tristón y flaco.

Y Cervantes, satisfecho ya con estas menciones descriptivas de su héroe, introduce el otro gran tema de su novela: el misterioso y lúdico poder de la escritura. De seguido a lo anterior añade: «Quieren decir que tenía el sobrenombre de Quijada o Quesada, que en esto hay alguna diferencia en los autores que de este caso escriben». Se imponen dos preguntas tan básicas como necesarias sobre las dudas acerca del apellido: ¿quiénes «quieren decir»?; ¿qué «autores» escriben de este caso? Desde ahora toda la historia de la novela es presentada como si no fuera obra de Cervantes, quien firma el libro sino, como se revela más adelante, obra de un tal Cide Hamete Benengeli, autor árabe de quien el narrador del Quijote sólo copia, luego de hacerlo traducir al castellano. Y aquí comienza afirmando yue son varios los autores de su historia. Pero además, ¿qué clase de 
historia es esta sobre un hombre anónimo? ¿No era la historia un género reservado para los grandes hombres? Tal vez en la tradición, pero la historia ficticia que Cervantes estaba fundando es la novela moderna, la crónica verosímil de los hombres anónimos, nuestros conocidos.

El caso de las fuentes mencionadas importa bien poco porque Cervantes ha descubierto que el lenguaje literario es independiente de la realidad; en él y con él todo es posible, incluso negarse a sí mismo, o darse una identidad diferente; ha descubierto que el lenguaje de la buena literatura no tiene límites, salvo uno fundamental: el de ser siempre verosímil, creíble, ni excesivo ni disparatado, ni menos, inconcebible.

Por eso, la duda del narrador entre Quijada o Quesada, o Quejana, que insinúa, otra vez, la gran pregunta de si existe este señor, si es, en efecto, una persona de apellido Quesada o Quijada, no importa que quede resuelta: este señor es, y es como sabemos que es él u otro como él. De tan creíble, de tan verosímil se nos va haciendo verdadero, no importa su apellido.

Así, además de suscitar la interrogante sobre quiénes escriben sobre él, abre otra vez el espacio a la credibilidad respecto de la existencia de alguna persona en efecto así llamada. Pero, en rigor, no hay otros autores que escriban sobre este personaje. Todo es pura creación de lenguaje y, naturalmente, es dificil pensar cómo se cntendería esta frase en 1605. Ahoranosotros la entendemos como una cspecie de doble ironía, porque cuando Cervantes introduce poco después la idea de que, en efecto, él leyó la historia de estapersona, don Quijote, contada por un tal Cide Hamete Benengeli, el lector tiene que haberse preguntado quién y cómo pudo haber escrito alguien sobre una persona tan anónima, un vecino tan común y corriente, un manchego pobretón de cincuenta años, y para colmo algo chalado. Nunca hubo ni había historiadores para personas así y, sin embargo, este iba a ser en adelante el gran personaje de la escritura, el héroe de la novela moderna, el centro de la literatura universal, el ser ordinario y 
cotidiano, y los hermosos caballeros andantes quedarían con sus proezas y hazañas para siempre en el olvido.

Y esto no es todo al respecto, porque al asunto de la duda de si era Quijada o Quesada, agrega: «Pero esto importa poco a nuestro cuento, basta que en la narración dél, no se salga un punto de la verdad». Estamos aquí ante una frase estremecedora y absolutamente nueva: Cervantes, desde el principio, propone su relato como verdadero, y su personaje como un ser real; así, ¿a cuál verdad se refiere? No está escribiendo una historia canónica pues no hay documentos ni antecedentes que lo respalden, salvo los que él inventa. Todo, se sabe bien, no es más que ficción, una «historia» creada por él; así, cuando dice que lo que importa es que la narración «no se salga un punto de la verdad» cabe volver a preguntarse de cuál verdad se habla, ¿de si existe esta persona o si existió o no esta persona?

La verdad de la que Cervantes está hablando, es la de la nueva novela moderna, es decir, la posibilidad de que este género crease un universo absolutamente verosímil por cercano, por conocido para nosotros, por realista, por próximo, pero aún así, ficticio. Esta nueva forma de ilusión terminó para siempre con la ilusión de la imaginación inverosímil, e instaló otra imaginación: la imaginación de lo cotidiano, la posibilidad de hacer novelas sobre la vida de nosotros mismos, o sobre la vida de nuestros semejantes, de nuestros conocidos. Aquí, pues, aparece la gran contribución de Cervantes a la cultura occidental y a la creación literaria: el lenguaje podía borrar los límites de la realidad necesaria, creando la suya propia, fundando mundos ficticios de aspecto real, del todo creíbles y verosímiles, como es la vida de todos los días, que desde entonces comenzó a ser el gran tema de la novela. Nunca más volvió aquella fantasía gratuita a dominar la literatura.

Ahora una pausa necesaria acerca de la palabra «cuento» aquí introducida por Cervantes: «importa poco a nuestro cuento», ha dicho. Aunque Sebastián de Covarrubias registra «cuento» bajo la voz «contar», entre cuyas acepciones registra la de «referir algún caso o 
acontecimiento», es claro que no tiene aún el sentido de relato literario, y menos aún el de género literario. Cejador y Frauca, por su parte, nos informa que en el Quijote se registra una veintena de casos en los que Cervantes emplea la voz «cuento» como sinónimo de narración; como simple sustantivo del verbo contar, sin alcances literarios específicos, uso que está en el castellano, y estaacepción, nos lo informa Corominas, aparece desde los primeros documentos del idioma ${ }^{5}$.

Y a continuación la causa del desvarío de «nuestro héroe»: los libros de caballería le han hecho perder la razón y el dinero. Libros que ya no conducían a nada, y para Cervantes, ni siquiera a la distracción. Era preciso darles fin, abrir otros horizontes al esparcimiento, a la imaginación y a la inteligencia, en fin, a la creatividad humana.

Ahora, como recordé al principio, ha vuelto la aventura inverosímil por medio del cine, de cierto cine; o de cierta literatura que suele identificarse como fantástica, pero la llamada gran literatura del mundo moderno quedó bajo el legado de Cervantes, desde ahí y para siempre marcada por su nombre y el modelo inconfundible de estos dos caros vecinos, Don Quijote y Sancho Panza.

Schastián de Covarrubias Orozco publicó en Madrid, en 1611, por las prensas de Luis Sánchez, su Te'soro de la lengua castellana, diccionario que Cervantes debió conocer. Hay una magnífica 'dicicon moderna a cargo de Martín de Riquer: Barcelona: S. A. Horta, 1943). Julio Cejador y I tiut i i es cl autor de La lengua de Cervantes. Gramática y diccionario de la lengua castellana '"l I I inge'mioso hidalgo don Quijote de La Mancha, cuyo tomo II es el Diccionario y comentaIII. (Midlricl: Isstablecimiento tipográfico de Jaime Rotes, 1605). Y por último nos referimos a luin ( inuminas, Diccionario crítico etimológico de la lengua castellana (Madrid: Gredos, (1) ill voll. I. s. v. contar. 